\title{
Effect of dynamic position changes on adenoma detection rate during colonoscope withdrawal: systematic review and meta-analysis
}

\section{(ㄷ)(우)}

\author{
Authors \\ Institutions \\ 1 Department of Gastroenterology, University of Kansas \\ Medical Center, Kansas City, Kansa, United States \\ 2 Department of Gastroenterology, Kansas City Veterans \\ Medical Center, Kansas City, Kansas, United States
}

Venkat Nutalapati ${ }^{1}$, Madhav Desai $^{2}$, Vivek Sandeep Thoguluva-Chandrasekar ${ }^{1}$, Mojtaba Olyaee $^{1}$, Amit Rastogi ${ }^{1}$

submitted 22.4.2020

accepted after revision 3.8 .2020

\section{Bibliography}

Endoscopy International Open 2020; 08: E1842-E1849

DOI 10.1055/a-1265-6634

ISSN 2364-3722

(C) 2020. The Author(s).

This is an open access article published by Thieme under the terms of the Creative Commons Attribution-NonDerivative-NonCommercial License, permitting copying and reproduction so long as the original work is given appropriate credit. Contents may not be used for commecial purposes, or adapted, remixed, transformed or built upon. (https://creativecommons.org/licenses/by-nc-nd/4.0/)

\section{Corresponding author}

Venkat Nutalapati, University of Kansas School of Medicine, Department of Internal Medicine, 3838 Rainbow Blvd, Apt 1105, Kansas City, Kansas 66103, United States

Fax: +1-913-588-5000

vnutalapati@kumc.edu

\section{ABSTRACT}

Background and study aims The adenoma detection rate $(A D R)$ is an important quality metric of colonoscopy. Higher ADR correlates with lower incidence of interval colorectal cancer. ADR is variable between endoscopists and depends upon the withdrawal technique amongst other factors. Dy- namic position change (lateral rotation of patients with a view to keep the portion of the colon being inspected at a higher level) helps with luminal distension during the withdrawal phase. However, impact of this on ADR is not known in a pooled sample. We performed a systematic review and meta-analysis to study the impact of dynamic position changes during withdrawal phase of colonoscopy on ADR Methods A comprehensive search of MEDLINE, EMBASE, Google Scholar, and the Cochrane Database was conducted from each database's inception to search for studies comparing dynamic position changes during colonoscope withdrawal with static left lateral position (control). The primary outcome of interest was ADR. Other studied outcomes were polyp detection rate (PDR) and withdrawal time. Outcomes were reported as pooled odds ratio (OR) with $95 \%$ confidence intervals $(\mathrm{Cl})$ with statistical significance $(P<$ 0.05 ). RevMan 5.3 software was used for statistical analysis. Results Six studies were included in our analysis with 2860 patients. Of these, dynamic position change was implemented in 1177 patients while 1183 patients served as the controls. ADR was significantly higher in the dynamic position change group with pooled OR 1.36 (95\% Cl, 1.15-1.61; $P<0.01)$. There was low heterogeneity in inclusion studies $\left(I^{2}=0 \%\right)$. PDR was numerically higher in position change group ( $53.4 \%$ vs $49.6 \%$ ) but not statistically significant ( $P=$ $0.16)$. Mean withdrawal time did not significantly change with dynamic position change (12.43 min vs $11.46 \mathrm{~min}, P=$ 0.27).

Conclusion Position change during the withdrawal phase of colonoscopy can increase the ADR compared to static left lateral position. This is an easy and practical technique that can be implemented to improve ADR.

\section{Introduction}

Colorectal cancer (CRC) is one of the most common malignancies in Western populations, including the United States. Colonoscopy is currently considered the gold standard method for diagnosis and removal of precancerous adenomatous polyps [1]. Current evidence points towards significant reduction in the incidence of CRC and associated mortality with removal of adenomatous polyps [2,3]. However, colonoscopy is far from perfect, with studies showing miss rates for both polyps and specifically adenomas ranging from $6 \%$ to $27 \%$ depending on size $[4,5]$. The adenoma detection rate (ADR) of endoscopists has been shown to be inversely related to the development of interval CRC [6]. Therefore, ADR is considered an important 
quality metric of colonoscopy and methods to improve it has been an active area of research. Amongst these are included good bowel prep, adequate withdrawal time, meticulous inspection technique, retroflexion in the right colon, and distal attachment devices to flatten the colonic folds.

The basic tenets of good inspection techniques include cleaning and suctioning residual liquid and solid debris, adequate luminal distension, and inspection behind folds [7, 8]. As opposed to distal attachment devices, meticulous inspection technique during withdrawal does not add extra cost to the procedure. Adequate luminal distention has been shown to improve visibility during colonoscope withdrawal [9]. Conventionally, colonoscopy is performed with the patient lying in the left lateral position. In this position the descending colon is dependent and therefore decompressed and retained fluid can also relocate to this segment making visualization less than optimal. Changing the patient position during the withdrawal phase can improve luminal distention. This concept originates from the experiences with barium enema and computed tomography (CT) colonography, where position change can promote adequate distension of the colon and the movement of excess fluid away from the area being observed [10]. The basic premise of position change is to bring the segment of colon being examined to the highest level, causing gas to rise to that area and fluid to move away to the dependent portion thereby resulting in adequate luminal distension. This can be achieved by having the patient in the left lateral position when examining the ascending colon, supine for transverse colon and in the right lateral position for the descending and sigmoid colon.

Currently, changing patient position during the withdrawal phase is not a routine practice. Reasons include time limitations, difficulty in moving sedated patients especially under deep sedation with propofol, and a lack of awareness regarding the potential benefits of position changes [11]. Previously it has been reported in randomized studies that there are benefits of changing patient position but the data have been conflicting [11-13]. We performed a systematic review and meta-analysis to examine the impact of dynamic patient position change during colonoscope withdrawal on adenoma detection rate (ADR) and polyp detection rate (PDR).

\section{Methods}

This systematic review and meta-analysis was performed according to the PRISMA guidelines [14]. The checklist is shown in Table 1.

\section{Search strategy}

An electronic search was performed in Pubmed (MEDLINE), EMBASE, Google Scholar, and the Cochrane Database. The search for studies of relevance was performed using the following search terms with corresponding Medical Subject Heading/Entree terms when appropriate: "colonoscopy", "adenoma detection rate (ADR)", "patient position" and/or "withdrawal”. Bibliography of eligible clinical study and review articles were manually searched. Two authors (V.N. and V.T.C) independently performed literature search and reviewed results. Duplicates were removed and retrieved titles and abstracts were screened for their eligibility. - Fig. 1 shows the process of literature review, screening of articles, and exclusion and final selection of studies.

\section{Eligibility}

Only controlled studies where effect of position change (i.e. intervention) during colonoscopy was examined with outcome of ADR compared to no intervention. We excluded any study that did not compare position change arm to control arm, or did not report $A D R, P D R$, and withdrawal times. We excluded review articles, non-human studies, abstract form only and editorials. Studies where definition of intervention was not clearly defined.

\section{Data extraction}

Two investigators (V.N. and V.T.C.) independently reviewed the eligible studies and extracted data into a standardized format into MS Excel. Data extracted were patient demographics, year of publication, study location, number of subjects, bowel preparation quality, position changes of the patient, ADR, PDR and withdrawal times among both arms. Individual characteristics have been listed in $>$ Table 2 .

\section{Outcomes}

The primary outcome of interest was ADR. Other studied outcomes were polyp detection rate (PDR) and withdrawal time, luminal distention score.

\section{Statistical analysis}

Pooled effect sizes for the meta-analyses were performed using Mantel-Haenszel method combining the effect sizes from different trials comparing position change and control arms. A fixed effects model was used as there is common effect in all studies and there is minimal/low heterogeneity $(I 2=0 \%)$ detected. Pooled odds ratio (OR) with corresponding $95 \% \mathrm{Cl}$ were calculated. Heterogeneity was calculated using $R^{2}$ test. Publication bias was assessed using funnel plot. The statistical analyses were performed using RevMan software (Review Manager version 5.3; The Nordic Cochrane Centre, Copenhagen, Demark, The Cochrane Collaboration 2015).

\section{Results}

Of 2834 records reviewed, a total of six studies were found eligible with 2860 patients (981 males, reported in 4 studies). Of these, dynamic position change was implemented in 1177 patients while 1183 patients served as the controls. The included studies employing different strategies to assess the effect of position changes. East et al and Ball et al employed randomized crossover techniques, where each patient had the colon examined twice: one with position changes and the other where no position changes were employed $[12,15]$. The remaining four studies employed randomization with 1:1 assignment for assessment of position changes $[11,13,16,17]$. The study characteristics and Jadad score (which has been used for quality assessment) have been shown in $>$ Table 2 . 
- Table 1 PRISMA checklist.

\begin{tabular}{|c|c|c|c|}
\hline Section/topic & $\#$ & Checklist item & $\begin{array}{l}\text { Reported } \\
\text { on page \# }\end{array}$ \\
\hline \multicolumn{4}{|l|}{ Title } \\
\hline Title & 1 & Identify the report as a systematic review, meta-analysis, or both. & 1 \\
\hline \multicolumn{4}{|l|}{ Abstract } \\
\hline Structured summary & 2 & $\begin{array}{l}\text { Provide a structured summary including, as applicable: background; objectives; data sources; } \\
\text { study eligibility criteria, participants, and interventions; study appraisal and synthesis methods; } \\
\text { results; limitations; conclusions and implications of key findings; systematic review registration } \\
\text { number. }\end{array}$ & 1 \\
\hline \multicolumn{4}{|l|}{ Introduction } \\
\hline Rationale & 3 & Describe the rationale for the review in the context of what is already known. & 2 \\
\hline Objectives & 4 & $\begin{array}{l}\text { Provide an explicit statement of questions being addressed with reference to participants, inter- } \\
\text { ventions, comparisons, outcomes, and study design (PICOS). }\end{array}$ & 2 \\
\hline \multicolumn{4}{|l|}{ Methods } \\
\hline $\begin{array}{l}\text { Protocol and registra- } \\
\text { tion }\end{array}$ & 5 & $\begin{array}{l}\text { Indicate if a review protocol exists, if and where it can be accessed (e. g., Web address), and, if } \\
\text { available, provide registration information including registration number. }\end{array}$ & 3 \\
\hline Eligibility criteria & 6 & $\begin{array}{l}\text { Specify study characteristics (e. g., PICOS, length of follow-up) and report characteristics (e. g., } \\
\text { years considered, language, publication status) used as criteria for eligibility, giving rationale. }\end{array}$ & 3 \\
\hline Information sources & 7 & $\begin{array}{l}\text { Describe all information sources (e. g., databases with dates of coverage, contact with study au- } \\
\text { thors to identify additional studies) in the search and date last searched. }\end{array}$ & 3 \\
\hline Search & 8 & $\begin{array}{l}\text { Present full electronic search strategy for at least one database, including any limits used, such } \\
\text { that it could be repeated. }\end{array}$ & 3 \\
\hline Study selection & 9 & $\begin{array}{l}\text { State the process for selecting studies (i. e., screening, eligibility, included in systematic review, } \\
\text { and, if applicable, included in the meta-analysis). }\end{array}$ & 3 \\
\hline $\begin{array}{l}\text { Data collection pro- } \\
\text { cess }\end{array}$ & 10 & $\begin{array}{l}\text { Describe method of data extraction from reports (e. g., piloted forms, independently, in dupli- } \\
\text { cate) and any processes for obtaining and confirming data from investigators. }\end{array}$ & 3 \\
\hline Data items & 11 & $\begin{array}{l}\text { List and define all variables for which data were sought (e. g., PICOS, funding sources) and any } \\
\text { assumptions and simplifications made. }\end{array}$ & 3 \\
\hline $\begin{array}{l}\text { Risk of bias in individ- } \\
\text { ual studies }\end{array}$ & 12 & $\begin{array}{l}\text { Describe methods used for assessing risk of bias of individual studies (including specification of } \\
\text { whether this was done at the study or outcome level), and how this information is to be used in } \\
\text { any data synthesis. }\end{array}$ & 5 \\
\hline Summary measures & 13 & State the principal summary measures (e. g., risk ratio, difference in means). & 5 \\
\hline Synthesis of results & 14 & $\begin{array}{l}\text { Describe the methods of handling data and combining results of studies, if done, including } \\
\text { measures of consistency (e. g., } \text { I }^{2} \text { ) for each meta-analysis. }\end{array}$ & 5 \\
\hline Section/topic & & $\begin{array}{l}\text { Checklist item } \\
\text { Reported on page \# }\end{array}$ & \\
\hline $\begin{array}{l}\text { Risk of bias across } \\
\text { studies }\end{array}$ & 15 & $\begin{array}{l}\text { Specify any assessment of risk of bias that may affect the cumulative evidence (e. g., publication } \\
\text { bias, selective reporting within studies). }\end{array}$ & 5 \\
\hline Additional analyses & 16 & $\begin{array}{l}\text { Describe methods of additional analyses (e. g., sensitivity or subgroup analyses, meta-regres- } \\
\text { sion), if done, indicating which were pre-specified. }\end{array}$ & 5 \\
\hline \multicolumn{4}{|l|}{ Results } \\
\hline Study selection & 17 & $\begin{array}{l}\text { Give numbers of studies screened, assessed for eligibility, and included in the review, with rea- } \\
\text { sons for exclusions at each stage, ideally with a flow diagram. }\end{array}$ & 5 \\
\hline Study characteristics & 18 & $\begin{array}{l}\text { For each study, present characteristics for which data were extracted (e. g., study size, PICOS, } \\
\text { follow-up period) and provide the citations. }\end{array}$ & 5 \\
\hline $\begin{array}{l}\text { Risk of bias within } \\
\text { studies }\end{array}$ & 19 & $\begin{array}{l}\text { Present data on risk of bias of each study and, if available, any outcome level assessment (see item } \\
\text { 12). }\end{array}$ & 5 \\
\hline $\begin{array}{l}\text { Results of individual } \\
\text { studies }\end{array}$ & 20 & $\begin{array}{l}\text { For all outcomes considered (benefits or harms), present, for each study: (a) simple summary } \\
\text { data for each intervention group (b) effect estimates and confidence intervals, ideally with a for- } \\
\text { est plot. }\end{array}$ & 5 \\
\hline
\end{tabular}


- Table 1 (Continuation)

\begin{tabular}{|l|l|l|l|}
\hline Section/topic & $\#$ & Checklist item & $\begin{array}{c}\text { Reported } \\
\text { on page \# }\end{array}$ \\
\hline Synthesis of results & 21 & $\begin{array}{l}\text { Present results of each meta-analysis done, including confidence intervals and measures of con- } \\
\text { sistency. }\end{array}$ \\
\hline $\begin{array}{l}\text { Risk of bias across } \\
\text { studies }\end{array}$ & 22 & Present results of any assessment of risk of bias across studies (see Item 15). \\
\hline Additional analysis & 23 & $\begin{array}{l}\text { Give results of additional analyses, if done (e. g., sensitivity or subgroup analyses, meta-regres- } \\
\text { sion [see Item 16]). }\end{array}$ \\
\hline Discussion & 24 & $\begin{array}{l}\text { Summarize the main findings including the strength of evidence for each main outcome; consider } \\
\text { their relevance to key groups (e. g., healthcare providers, users, and policy makers). }\end{array}$ \\
\hline Summary of evidence & 25 & $\begin{array}{l}\text { Discuss limitations at study and outcome level (e. g., risk of bias), and at review-level (e. g., in- } \\
\text { complete retrieval of identified research, reporting bias). }\end{array}$ \\
\hline Limitations & 26 & $\begin{array}{l}\text { Provide a general interpretation of the results in the context of other evidence, and implications } \\
\text { for future research. }\end{array}$ \\
\hline Conclusions & 6 & 6 \\
\hline Funding & 27 & $\begin{array}{l}\text { Describe sources of funding for the systematic review and other support (e. g., supply of data); } \\
\text { role of funders for the systematic review. }\end{array}$ \\
\hline Funding & None (1) \\
\hline
\end{tabular}

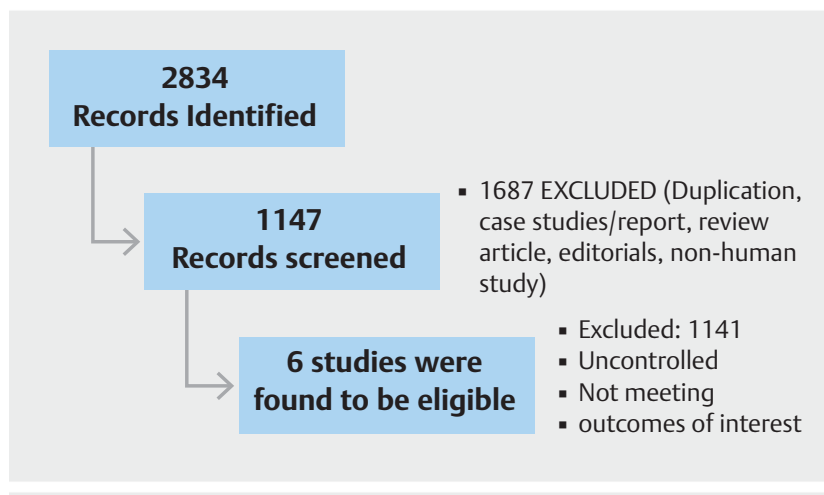

> Fig. 1 Flowchart.

\section{Adenoma detection rate}

ADR was reported in all six studies. Pooled ADR was $41.63 \%$ $(490 / 1177)$ in the dynamic position change group compared to $34.48 \%(408 / 1183)$ in the control group. ADR was significantly higher in the dynamic position change group with pooled OR $1.36(95 \% \mathrm{Cl}, 1.15-1.61 ; P<0.01)$ ( $\mathbf{F i g . 2}$ ). There was low heterogeneity in included studies $\left(I^{2}=0 \%\right)$. The number needed to find one additional patient with at least one adenoma was 14.

When an analysis was performed for studies with Jadad score $\geq 3$, results did not change significantly. Pooled OR was 1.35 with $95 \% \mathrm{Cl} 1.13-1.62$ in favor of the position change arm.

\section{Polyp detection rate}

PDR was reported in four studies. PDR was 53.35\% (302/566) in the dynamic position change group compared to $49.65 \%$ (284/572). PDR was not significantly different between the 2 groups with a pooled $\mathrm{OR}=1.32(95 \% \mathrm{Cl}, 0.9-1.93 ; P=0.16)$ ( Fig.3). There was moderate heterogeneity in inclusion studies $\left(I^{2}=40 \%\right)$.

\section{Withdrawal times}

Withdrawal times were reported in a total of four studies in minutes. Mean withdrawal time in the dynamic position change group was 12.43 minutes vs 11.46 minutes in the standard group, $P=0.27$. The withdrawl times included stoppage of clock for position changes and when interventions were performed, except for one study which used 6 minutes as withdrawal with 2 minutes per each section of the colon [9].

\section{Luminal distention score}

Two studies also reported correlation between luminal distension and ADR or PDR. One study showed ADR and PDR were positively correlated with an improved distension score (correlation coefficient, $0.12 ; P<.001$ ) with other study showing no significant correlation between luminal distension and the number of polyps in the right side of the colon $(r=0.03 ; P=0.69)$, the transverse colon $(r=-0.05 ; P=0.47)$ or the left side of the colon $(r=-0.05 ; P=0.54) .(r=0.03)[12,15]$.

\section{Publication bias}

Funnel plot is shown in - Fig. 4. There was no asymmetry suggestive of no significant publication bias.

\section{Discussion}

In this meta-analysis we show that the employment of dynamic position change during withdrawal phase of colonoscopy is associated with increased ADR. ADR is the main quality indicator of colonoscopy and it is inversely related to the incidence of 
- Table2 Study characteristics, patient demographics.

\begin{tabular}{|c|c|c|c|c|c|c|c|}
\hline Study & $\begin{array}{l}\text { Study } \\
\text { design }\end{array}$ & $\begin{array}{l}\text { Jadad } \\
\text { score }\end{array}$ & $\begin{array}{l}\text { Bowel } \\
\text { prepara- } \\
\text { tion }\end{array}$ & $\begin{array}{l}\text { Pa- } \\
\text { tients } \\
\text { (male) }\end{array}$ & $\begin{array}{l}\text { Regions } \\
\text { of exami- } \\
\text { nation }\end{array}$ & Country & Position changes \\
\hline $\begin{array}{l}\text { East } \\
\text { et al } \\
{[12]}\end{array}$ & $\begin{array}{l}\text { Randomized } \\
\text { cross-over } \\
\text { study }\end{array}$ & 3 & $\begin{array}{l}\text { Good, } \\
\text { Ade- } \\
\text { quate }\end{array}$ & 70 & $\begin{array}{l}\text { Cecum to } \\
\text { descend- } \\
\text { ing colon }\end{array}$ & UK & $\begin{array}{l}\text { Cecum, ascending colon, and hepatic flexure: left } \\
\text { lateral position; transverse colon: supine position; } \\
\text { splenic flexure and descending colon: right lateral } \\
\text { position }\end{array}$ \\
\hline $\begin{array}{l}\text { Kök- } \\
\text { sal et } \\
\text { al [13] }\end{array}$ & $\begin{array}{l}\text { Randomized } \\
\text { cross-over } \\
\text { study }\end{array}$ & 2 & NA & 50 & $\begin{array}{l}\text { Cecum to } \\
\text { sigmoid } \\
\text { colon }\end{array}$ & Turkey & $\begin{array}{l}\text { Cecum, ascending colon and hepatic flexure; } \\
\text { transverse colon; and splenic flexure, descending } \\
\text { colon and sigmoid colon. The first region was ex- } \\
\text { amined in the left lateral position twice. The sec- } \\
\text { ond region was examined in the left lateral and su- } \\
\text { pine positions. The third region was examined in } \\
\text { the left lateral, right lateral and supine positions }\end{array}$ \\
\hline $\begin{array}{l}\text { Ya- } \\
\text { ma- } \\
\text { guchi } \\
\text { et al } \\
{[17]}\end{array}$ & $\begin{array}{l}\text { Randomized } \\
\text { parallel- } \\
\text { group study }\end{array}$ & 2 & NA & 98 & $\begin{array}{l}\text { Cecum to } \\
\text { rectum }\end{array}$ & Japan & $\begin{array}{l}\text { Examination in the supine position was followed by } \\
\text { either the following dynamic position changes (ce- } \\
\text { cum to transverse colon, supine; splenic flexure } \\
\text { and descending colon, right lateral; sigmoid colon, } \\
\text { supine; and rectum, left lateral) or minimal posi- } \\
\text { tion changes (cecum to sigmoid colon, supine; and } \\
\text { rectum, left lateral) }\end{array}$ \\
\hline $\begin{array}{l}\text { Ball et } \\
\text { al [15] }\end{array}$ & $\begin{array}{l}\text { Randomized } \\
\text { cross-over } \\
\text { study }\end{array}$ & 1 & NA & 130 & $\begin{array}{l}\text { Cecum to } \\
\text { descend- } \\
\text { ing colon }\end{array}$ & UK & $\begin{array}{l}\text { The position change was left lateral position for } \\
\text { examination of the right side of the colon(cecum, } \\
\text { ascending colon, and hepatic flexure) and right } \\
\text { lateral position for examination of the left side of } \\
\text { the colon(splenic flexure and descending colon but } \\
\text { not including the sigmoid colon). }\end{array}$ \\
\hline $\begin{array}{l}\text { Ou et } \\
\text { al [11] }\end{array}$ & $\begin{array}{l}\text { Randomized } \\
\text { parallel- } \\
\text { group study }\end{array}$ & 3 & $\begin{array}{l}\text { Fair, } \\
\text { good } \\
\text { and ex- } \\
\text { cellent }\end{array}$ & 355 & $\begin{array}{l}\text { Ascend- } \\
\text { ing colon } \\
\text { to rectum }\end{array}$ & Canada & $\begin{array}{l}\text { Ascending colon/hepatic flexure examined in left } \\
\text { lateral decubitus position, transverse colon in su- } \\
\text { pine position, and splenic flexure/descending co- } \\
\text { lon/sigmoid colon/rectum in right lateral decubi- } \\
\text { tus position }\end{array}$ \\
\hline $\begin{array}{l}\text { Lee et } \\
\text { al [16] }\end{array}$ & $\begin{array}{l}\text { Randomized } \\
\text { multicenter } \\
\text { parallel- } \\
\text { group study }\end{array}$ & 3 & $\begin{array}{l}\text { Excel- } \\
\text { lent, } \\
\text { Good } \\
\text { and Fair }\end{array}$ & 506 & $\begin{array}{l}\text { Cecum to } \\
\text { rectum }\end{array}$ & Korea & $\begin{array}{l}\text { Cecum, ascending colon, and hepatic flexure: left } \\
\text { lateral position; transverse colon: supine position; } \\
\text { splenic flexure, descending colon, sigmoid colon, } \\
\text { and rectum: right lateral position }\end{array}$ \\
\hline
\end{tabular}

NA, not available.

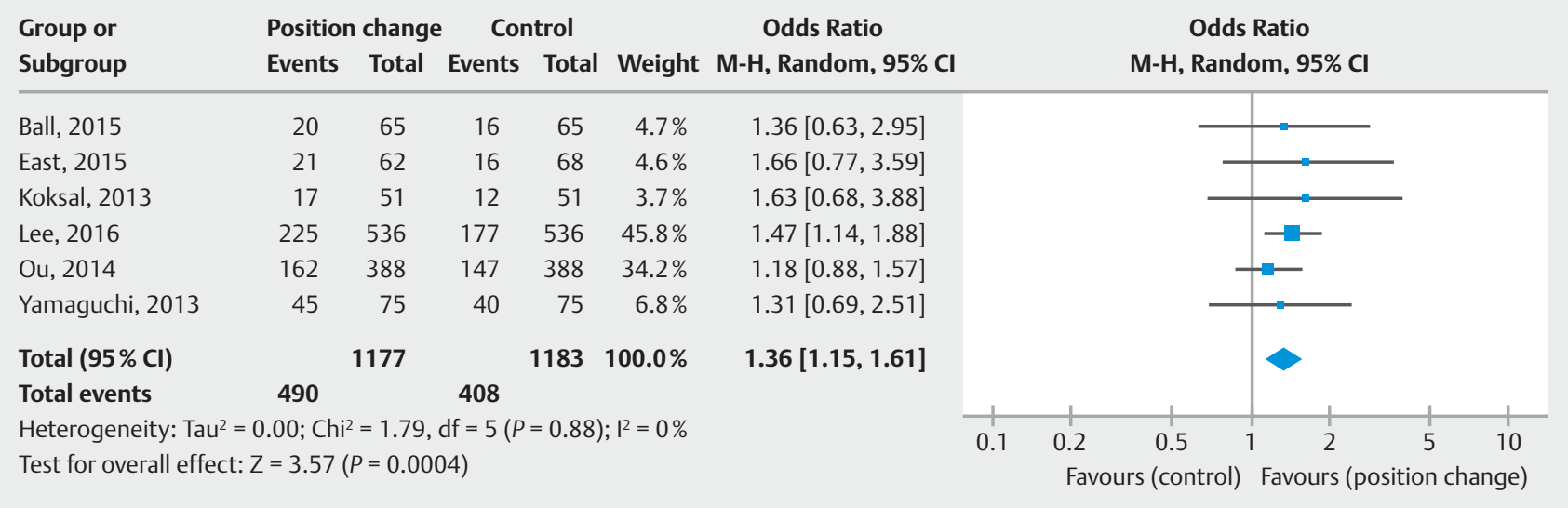

Fig. 2 Forest plot of ADR. 


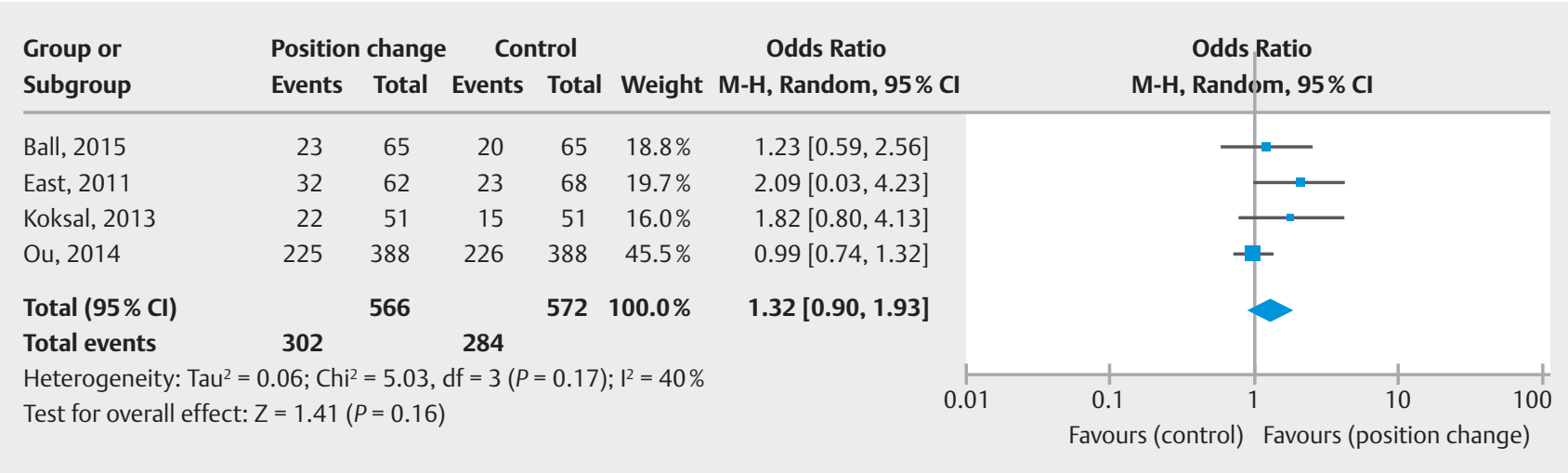

- Fig. 3 Forest plot of PDR.

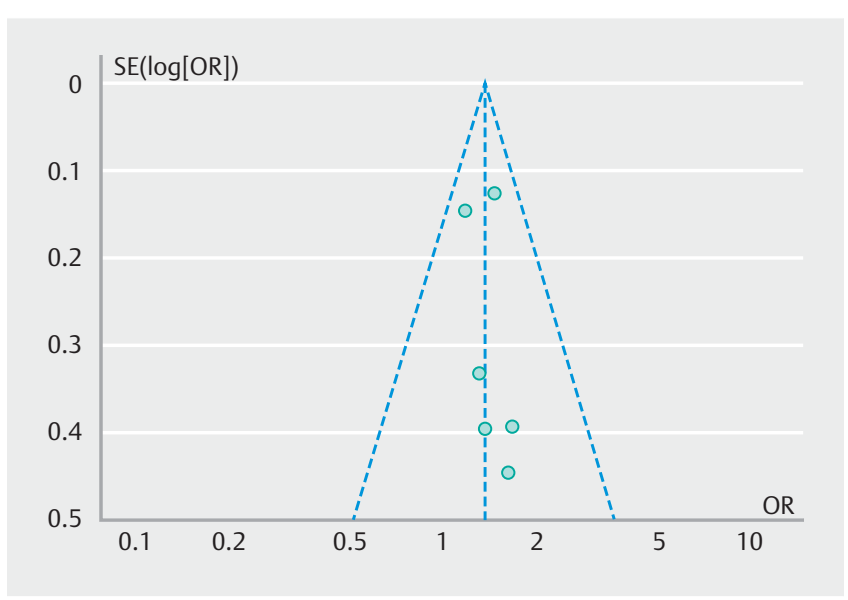

Fig. 4 Publication bias funnel plot.

interval cancer in patients [6]. Therefore, dynamic position change to bring the segment of the colon being examined to the highest position, thereby improving luminal distension and visualization is a simple and inexpensive means to improve the quality of colonoscopy. However, we did not find a statistical difference in two arms for PDR despite noting a higher PDR in intervention group compared to control group. This could be from several factors including but not limited to: small number of studies reporting PDR $(n=4)$, less significance of overall PDR (i.e. distal hyperplastic polyp), lack of information on diminutive and serrated polyps.

Several studies have explored the impact of dynamic position change on ADR and showed heterogenous results. Crossover studies by East et al and Koksal et al noted an approximately $10 \%$ increase in ADR, which was significant with most prominent improvement in adenoma detection in the transverse coIon in supine position $[12,13]$. In the two-way crossover study by Ball et al, an improvement in luminal distension was observed in the right colon in the left lateral position and in the left colon in the right lateral position. They compared patients in dynamic position changes with patients who were supine only throughout the withdrawal phase [15]. However, the left side of the colon with the patient in the right lateral position did not significantly increase the proportion of patients with $\geq 1$ polyp and $\geq 1$ adenoma compared with the supine position (7/130 [5.4\%] vs 6/130 [4.6\%], OR 1.2; $P=0.99$ and $4 / 130$ [3.1] vs $4 / 130$ [3.1], OR $1.0 ; P=0.66$, respectively) [15]. In the study by $\mathrm{Ou}$ et al, a single-center, parallel-group study compared ADR with dynamic position changes to that in usual practice. In this study the control group had endoscopists perform the colonoscopies using their usual practices, which involved position changes as deemed necessary [11]. Dynamic position changes during colonoscope withdrawal did not improve the ADR (41.8 vs. $37.9 \%, P=0.28)$.[11] In the study by Lee et al, a large-scale, multicenter, randomized, and parallelgroup design showed that ADR was higher in the position change group than in the control group (42.4 vs. $33.0 \%, P=$ 0.002 ). The authors further reported significantly higher detection of adenomas in the transverse colon and left colon [16]. Studies from East et al and Ball et al, also reported a correlation between luminal distension and ADR or PDR. One study showed that ADR and PDR were positively correlated with an improved distension score (correlation coefficient, $0.12 ; P<.001)$ and another study showed no significant correlation between luminal distension and polyp detection in the right side of the colon $[12,15]$.

The three basic components of good withdrawal technique are adequate luminal distension, cleaning and suctioning fluid and solid debris, and inspection behind the folds. Position changes during the withdrawal phase are one of the simplest maneuvers that can be employed for enhancing luminal distention given natural rise of air $/ \mathrm{CO}_{2}$ to highest position [18]. Adequate luminal distension is imperative for good visualization for adenoma detection. Furthermore, position change also shifts fluid away from the area of interest and opens the angles at flexures $[10,19]$. Although other methods such as prolonged insufflation may achieve adequate colonic luminal distension, they may not necessarily achieve the same increase in ADR as position changes [12]. In addition, it is often difficult to distend the segment of colon that is in the dependent position in spite of our best attempts at insufflation. Another word of caution with respect to aggressive insufflation is post-procedural abdominal discomfort. Although dynamic position of a sedated patient may take some time and effort thereby increase the 
duration of the procedure, this may be offset by less time required for insufflating and suctioning fluid. Furthermore, faster dispositions and discharge from the recovery unit may be possible stemming from decreased gaseous distension after the procedure [9] However these remain to be systematically evaluated and proven.

Our meta-analysis has some limitations. The number of studies that could be included was relatively small, but the study population was very diverse with studies being performed in Asia, North America, and Europe. This improves the generalizability of the results. Furthermore, we have more studies included than the previous network meta-analysis [20]. The goal of the prior study was comparison of all available modalities including any electronic chromoendoscopy techniques and modification of colonoscopy techniques for ADR. For separate analysis of position change, only one study was included due to their criteria. In comparison, our study is most current systematic review and meta-analysis on dynamic position change and its impact on ADR. Due to the obvious lack of blinding of the endoscopists, that is unavoidable in these types of studies, investigator bias is possible. This may lead to a more meticulous exam performed in those patients in the dynamic position change arm. The experience/skill of endoscopists in the different studies also varied widely and could not be accounted for with respect to the impact on ADR. The ADR increase with dynamic position change is modest, which would therefore have an even lower impact on the incidence of interval cancer. We also understand our analysis is a largely driven by two studies, Lee let al and Ou et al. As Ou et al. had turning in the control arm in $45 \%$ of patients resulting in some dilution of the "control" aspect in pooled estimate, we performed an analysis excluding this study. Our results for ADR with position change remained unchanged with pooled OR 1.46 (1.19-1.80; $P<0.01)$. There is also a lack of information regarding adhesions and diverticulosis, sedation requirements for elderly and their effects on colon segment examination. We also realize the limitation of dynamic positioning in certain patient populations (obese, critically ill, sleep apnea). Furthermore, there was a lack of detailed information regarding bowel preparation and withdrawl times (position changes included) in some studies or the effect of position change on advanced adenomas. It is also not clear from the studies whether the reported withdrawal time included the time needed to change the position of the patient that could be substantial especially with deep sedation. No details regarding post procedural discomfort and recovery was available in the studies either.

There have been other methods described to improve mucosal inspection especially the areas on the proximal aspects of folds. Distal attachments like the cap, Endorings, and Endocuff that flatten the folds have shown to improve ADR but come with an additional and not negligible cost. These distal attachment devices not only add to the cost of colonoscopy but offer only a modest improvement in ADR as was shown in a recent network meta-analysis [21]. Retroflexion of the colonoscope is also a simple and effective technique to improve ADR but is limited to the right colon. In contrast, dynamic position change can be effective for all segments of the colon and entails no ex- tra cost and thereby is an inexpensive and effective means to improve ADR. Many of the studies in this area come from the UK, where unsedated/low-level sedation colonoscopy is much more prevalent than in the United States. Turning patients who are under deep sedation with propofol would be more problematic and labor-intensive, and this appears to be the only perceivable drawback of dynamic position change.

\section{Conclusion}

In conclusion, this meta-analysis shows that dynamic position change during the withdrawal phase of colonoscopy is associated with increased ADR. We suggest left lateral position for right colon, supine positioning for transverse, and right lateral position for left side of the colon during withdrawal. This is a simple, safe, and inexpensive method that can be easily employed in routine clinical practice to improve the quality of colonoscopy.

\section{Competing interests}

The authors declare that they have no conflict of interest.

References

[1] Lieberman DA. Clinical practice. Screening for colorectal cancer. N Engl J Med 2009; 361: 1179-1187

[2] Baxter NN, Goldwasser MA, Paszat LF et al. Association of colonoscopy and death from colorectal cancer. Ann Intern Med 2009; 150: 1-8

[3] Brenner H, Chang-Claude J, Seiler CM et al. Protection from colorectal cancer after colonoscopy: a population-based, case-control study. Ann Intern Med 2011; 154: 22-30

[4] Rex DK, Cutler CS, Lemmel GT et al. Colonoscopic miss rates of adenomas determined by back-to-back colonoscopies. Gastroenterology 1997; 112: 24-28

[5] van Rijn JC, Reitsma JB, Stoker J et al. Polyp miss rate determined by tandem colonoscopy: a systematic review. Am J Gastroenterol 2006; 101: 343-350

[6] Kaminski MF, Regula J, Kraszewska E et al. Quality indicators for colonoscopy and the risk of interval cancer. N Engl J Med 2010; 362: 1795-1803

[7] Lee RH, Tang RS, Muthusamy VR et al. Quality of colonoscopy withdrawal technique and variability in adenoma detection rates (with videos). Gastrointest Endosc 2011; 74: 128-134

[8] Rex DK. Colonoscopic withdrawal technique is associated with adenoma miss rates. Gastrointest Endosc 2000; 51: 33-36

[9] East JE, Suzuki N, Arebi N et al. Position changes improve visibility during colonoscope withdrawal: a randomized, blinded, crossover trial. Gastrointest Endosc 2007; 65: 263-269

[10] Chen SC, Lu DS, Hecht JR et al. CT colonography: value of scanning in both the supine and prone positions. AJR Am J Roentgenol 1999; 172: 595-599

[11] Ou G, Kim E, Lakzadeh P et al. A randomized controlled trial assessing the effect of prescribed patient position changes during colonoscope withdrawal on adenoma detection. Gastrointest Endosc 2014; 80: 277-283

[12] East JE, Bassett P, Arebi $\mathrm{N}$ et al. Dynamic patient position changes during colonoscope withdrawal increase adenoma detection: a randomized, crossover trial. Gastrointest Endosc 2011; 73: 456-463 
[13] Koksal AS, Kalkan IH, Torun S et al. A simple method to improve adenoma detection rate during colonoscopy: altering patient position. Can J Gastroenterol 2013; 27: 509-512

[14] Moher D, Shamseer L, Clarke M et al. Preferred reporting items for systematic review and meta-analysis protocols (PRISMA-P) 2015 statement. Syst Rev 2015; 4: 1

[15] Ball AJ, Johal SS, Riley SA. Position change during colonoscope withdrawal increases polyp and adenoma detection in the right but not in the left side of the colon: results of a randomized controlled trial. Gastrointest Endosc 2015; 82: 488-494

[16] Lee SW, Chang JH, Ji JS et al. Effect of Dynamic position changes on adenoma detection during colonoscope withdrawal: a randomized controlled multicenter trial. Am J Gastroenterol 2016; 111: 63-69

[17] Yamaguchi KMK, Nakagawa Y, Hayashi M. Dynamic position changes during the colonoscope withdrawal phase decrease abdominal fullness. Chiba Medical Journal 2013: 9-14
[18] Ghosh S, lacucci M. Dynamic position change at colonoscopy improves adenoma detection. Can J Gastroenterol 2013; 27: 508

[19] Fletcher JG, Johnson CD, Welch TJ et al. Optimization of CT colonography technique: prospective trial in 180 patients. Radiology 2000; 216: 704-711

[20] Facciorusso A, Triantafyllou K, Murad MH et al. Compared abilities of endoscopic techniques to increase colon adenoma detection rates: a network meta-analysis. Clin Gastroenterol Hepatol 2019; 17: 24392454

[21] Facciorusso A, Del Prete V, Buccino RV et al. Comparative efficacy of colonoscope distal attachment devices in increasing rates of adenoma detection: a network meta-analysis. Clin Gastroenterol Hepatol 2018; 16: 1209-1219 e1209 